\title{
ПРОБЛЕМЫ ОПРЕДЕЛЕНИЯ НИТРАТ-ИОНА В ОВОЩАХ ФИЗИКО-ХИМИЧЕСКИМИ МЕТОДАМИ
}

\author{
(Представил О. Киррет)
}

В результате применения в сельском хозяйстве интенсивных технологий возросло значение санитарно-гигиенической оценки содержания нитрат-иона в пищевых продуктах, представляющих собой сложные биологические системы, содержащие соли как неорганических, так и органических кислот.

Для определения нитрат-иона ['] широко применяются физико-химические методы: колориметрические, электрохимические, хроматографические и т.д. Среди последних одним из наиболее перспективных признан метод ионной хроматографии $\left[{ }^{2-4}\right]$, особенно в связи с выпуском отечественных ионных хроматографов, снабженных колонками для разделения анионов $\left[{ }^{5,6}\right]$. Разработан и внедрен в производство отечественный сорбент для ионной хроматографии [5]. Из электрохимических методов в практике санитарного контроля, благодаря экспрессности анализа, все шире используется потенциометрический с применением ионоселективных электродов $\left[{ }^{7-9}\right]$. Свое место в системе контроля сохранили и колориметрические методы, как наиболее точные и достаточно чувствительные [10].

Цель настоящей работы - сравнение результатов определения нитрат-иона тремя методами: колориметрическим, ионохроматографическим и ионометрическим.

\section{Экспериментальная часть}

Подготовка проб к определению $\mathrm{NO}_{3}^{-}$колориметрическим методом. Навеску овощей массой $1-20$ г измельчали, помещали в конические колбы емкостью $200 \mathrm{~cm}^{3}$, добавляли $5 \mathrm{~cm}^{3} 2,6 \%$-ного раствора $\mathrm{Na}_{2} \mathrm{~B}_{4} \mathrm{O}_{7}$ и $100 \mathrm{~cm}^{3}$ горячей дистиллированной воды $\left(70^{\circ} \mathrm{C}\right)$. Колбы выдерживали 15 мин на водяной бане $\left(70^{\circ} \mathrm{C}\right)$, периодически встряхивая. Затем последовательно добавляли по $2 \mathrm{~cm}^{3} \quad 9,2 \%$-ного раствора $\mathrm{K}_{4}\left[\mathrm{Fe}(\mathrm{CN})_{6}\right]$ и $18 \%$-ного раствора $\mathrm{Zn}\left(\mathrm{CH}_{3} \mathrm{COO}\right)_{2}$, перемешивая раствор после каждого добавления. Пробы охлаждали, дистиллированной водой доводили их массу до 200 г и пропускали через бумажный фильтр [11, 12].

Подготовка проб к определению $\mathrm{NO}_{3}^{-}$ионохроматографическим методом. Для одноколоночного варианта ионной хроматографии $\mathrm{c}$ использованием детектора по УФ-абсорбции пробы готовили так же, как в случае колориметрического метода определения нитрат-иона. При использовании ионохроматографической системы с подавлением электропроводности элюента к навескам измельченных овощей по 5 г добавляли $10 \mathrm{~cm}^{3}$ дистиллированной воды, $10 \mathrm{~cm}^{3}$ этанола и $2 \mathrm{~cm}^{3} 2 \%$-ного раствора $\mathrm{Ba}(\mathrm{OH})_{2}$. Полученную смесь встряхивали 5 мин и центрифугировали. Отбирали 5 см $^{3}$ центрифугата, добавляли 5 см $^{3} 10$ мM раствора $\mathrm{Na}_{2} \mathrm{CO}_{3}$, перемешивали и пропускали через бумажный фильтр. 
Подготовка проб к определению $\mathrm{NO}_{3}^{-}$ионометрическим методом. $\mathrm{K}$ навескам измельченных овощей по 1-10 г добавляли $1 \%$-ный раствор $\mathrm{KAl}\left(\mathrm{SO}_{4}\right)_{2}$. Перед измерениями полученную смесь взбалтывали 5 мин.

Аппаратура и методика определения $\mathrm{NO}_{3}^{-}$колориметрическим методом. Восстановление нитрат-иона до $\mathrm{NO}_{2}^{-}$осуществляли порошком $\mathrm{Cd}$ в колонках (вариант 1) или в круглодонных колбах встряхиванием Cd (вариант 2) [ $\left.{ }^{8}\right]$. Образовавшиеся нитрит-ионы определяли реактивом Грисса (сульфаниловая кислота и 1-нафтиламин) либо с помощью сульфаниламида и $\mathrm{N}$-(нафтил-1) -этилендиамина $[1,10]$. В первом случае протекают реакции диазотирования и сочетания
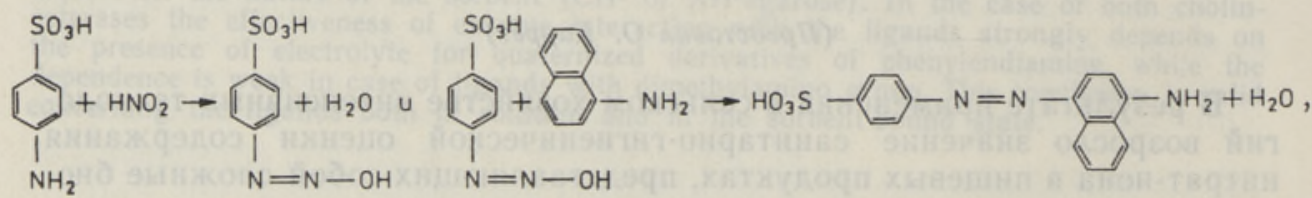

во втором случае - реакции $\left[{ }^{13}\right]$
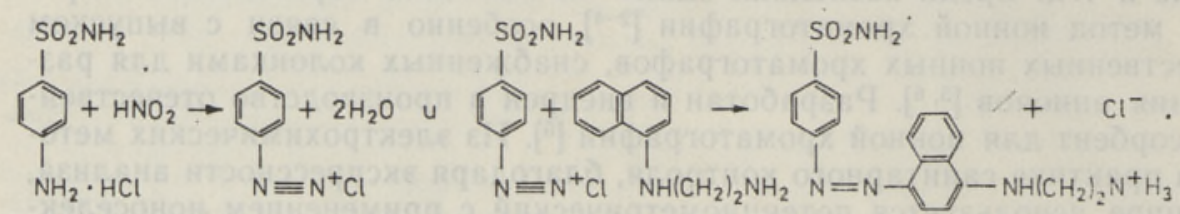

Для измерения оптической плотности растворов применяли спектроколориметр «Spekol 10» («Carl Zeiss», ГДР).

Аппаратура и методика определения $\mathrm{NO}_{3}^{-}$ионохроматографическим

методом. Одноколоночный ионный хроматограф состоял из насоса («Milton Roy», США), дозатора с объемом пробы 0,1 см$^{3}$ (СКБ АН ЭССР), разделяющей колонки $250 \times 3$ мм (сорбент ХИКС-1 [5]) и детектора по УФ-абсорбции («Милихром», СССР). Подготовленные пробы, а также растворы для калибровки хроматографировали на длине волны детектора 214 нм. Калибровочную кривую строили в координатах высота пика-концентрация нитрат-иона.

Двухколоночный ионный хроматограф имел, кроме разделяющей, еще и подавительную колонку с катионитом КУ-2 (фракция 60-90 мкм) размерами $300 \times 4,0$ мм. Применяли кондуктометрический детектор JD-1 (СКБ АН ЭССР). Подготовленные пробы, а также растворы для калибровки хроматографировали при чувствительности детектора 0,1 мСм на шкалу самописца. Калибровочную кривую строили в координатах высота пика-концентрация нитрат-иона.

Аппаратура и методика определения $\mathrm{NO}_{3}^{-}$ионометрическим методом. Использовали рН-метр типа OP-208 («Radelkis», Венгрия), ионоселективные электроды ЭМ-NO--01 (отечественного производства) и $\mathrm{F} 1012 \mathrm{Cl}$ («Radiometer», Дания).

Методика ионометрического определения включает построение калибровочного графика (используются стандартные растворы $10^{-4}-10^{-2} \mathrm{M}$ по $\mathrm{NO}_{3}^{-}$) и определение концентрации $\mathrm{NO}_{3}^{-}$в пробе по графику, построенному в координатах потенциал электрода-логарифм концентрации нитрат-иона. 


\section{Результаты и обсуждение}

Колориметрический метод, как наиболее проработанный [1,10,11], мы решили использовать в качестве основного и проверяли относительно его другие методы. В колориметрических измерениях погрешности возникают либо из-за недостаточной чистоты применяемых реактивов, либо из-за неучета влияния матрицы пробы на процесс восстановления нитратиона. Относительно 2-го варианта метода есть данные, что ухудшение воспроизводимости происходит из-за смещения $\mathrm{pH}$ буферного раствора под действием содержащихся в пробе полифосфатов [12] и может быть устранено повышением концентрации буферного раствора и увеличением навески порошка $\mathrm{Cd}\left[{ }^{10}\right]$.

Реакции диазотирования и сочетания также подвержены влиянию присутствующих в овощах или добавляемых к овощам восстановителей - аскорбиновой кислоты и сульфитов $\left[{ }^{12}\right]$. Влияние восстановителей устраняется разложением их с $\mathrm{KMnO}_{4}$ в щелочном растворе с последующим удалением избытка окислителя $\mathrm{AsO}_{3}^{3-}\left[{ }^{10,12}\right]$. Полученные нами и приведенные в $\left[{ }^{8,12}\right]$ данные свидетельствуют о том, что удаление аскорбиновой кислоты необходимо при определении содержаний нитратиона до 40 мг/सг для картофеля и до 30 мг/кг для капусты и брюквы. Найдено [12] и нами подтверждено, что длительная экстракция (15 мин-2 ч) также способствует устранению действия аскорбиновой кислоты.

Чтобы снизить погрешности калибровки, испытывались разные реагенты как для диазотирования, так и для сочетания $[1,10]$. Нами применен реактив Грисса, а также сульфаниламид и N-(нафтил-1) -этилендиамин. Изучение зависимости погрешности калибровки (стандартное отклонение точек относительно найденной оптимальной прямой $\left[{ }^{14}\right]$ $s_{\mathrm{T}}$ ) от типа реактива и времени проведения реакции (рис. 1) показало, что оптимальное время реакции с реактивом Грисса составляет 135 мин, а с сульфаниламидом и $\mathrm{N}$-(нафтил-1) -этилендиамином -50 мин.

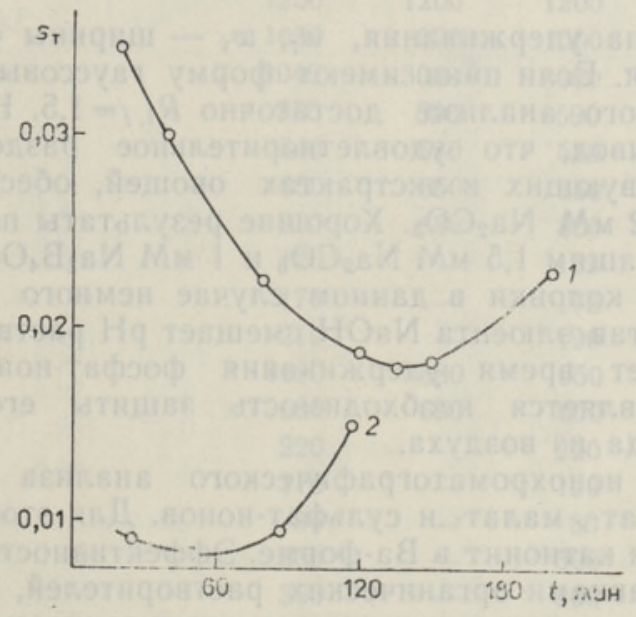

Рис. 1. Зависимость погрешности калибровки $\left(s_{\mathrm{T}}\right)$ от времени проведения реакции $(t)$ и применяемых реагентов. Температура $20^{\circ} \mathrm{C}$. 1 - реактив Грисса, $2-\mathrm{N}$-(нафтил-1) этилендиамин и сульфаниламид. 
Оิсновные погрешности при ионохроматографических методах опредеёления нитрат-иона возникают из-за недостаточной селективности либо эффективности хроматографической системы. Основные помехи создают фосфат- и малат-ионы [15, 16]. Так, содержание яблочной кислоты в картофеле может достигать 360-1490 мг/кг [15], а содержание фосфат-иона $500-900 \mathrm{Mr} / \mathrm{Kr}\left[{ }^{17}\right]$.

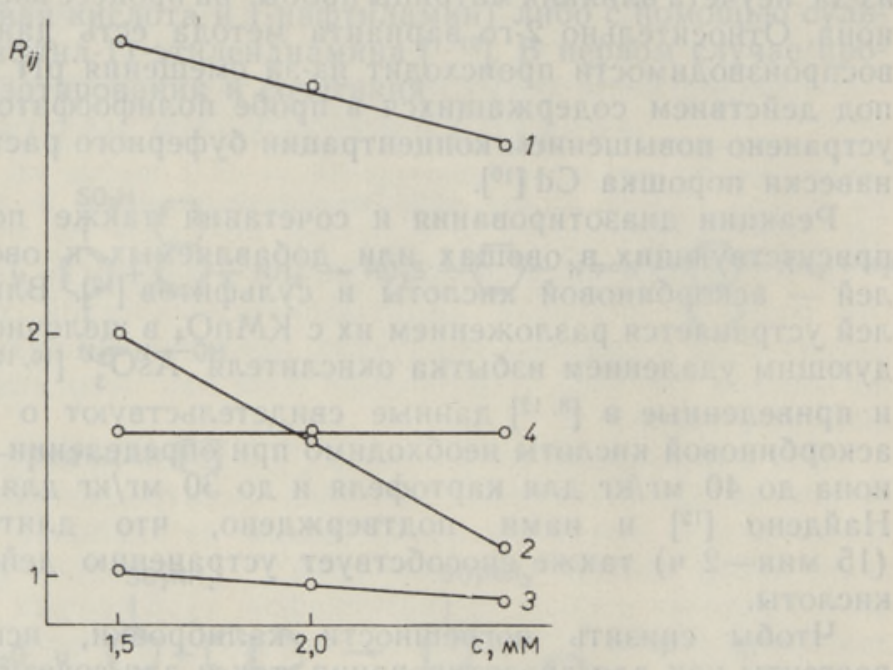

Рис. 2. Зависимость разделения $\left(R_{i j}\right)$ от концентрации элюента $(c)$. Размеры колонки $250 \times 3$ мм; сорбент ХИКС-1, обменная емкость $0,08 \mathrm{mM} / \mathrm{r}$; элюент - водный раствор $\mathrm{Na}_{2} \mathrm{CO}_{3}$, объемная скорость подачи $2,4 \mathrm{~cm}^{3} /$ мнн.

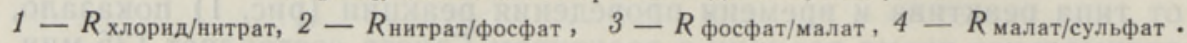

Для расчета зависимости разделения анионов $\left(R_{i, j}\right)$ на ионохроматографическом сорбенте ХИКС-1 от концентрации элюента (рис. 2) использовали формулу $\left[{ }^{18}\right]$ :

$$
R_{i, j}=2\left(t_{j}-t_{i}\right) /\left(w_{i}+w_{j}\right),
$$

где $t_{j}, t_{i}$ - времена удерживания, $w_{i}, w_{i}$ - ширины соответствующих пиков у основания. Если пики имеют форму гауссовых кривых, тогда для количественного анализа достаточно $R_{i, j}=1,5$. На основе рис. 2 можно сделать вывод, что удовлетворительное разделение основных анионов, присутствующих в экстрактах овощей, обеспечивает элюент с концентрацией 2 мM $\mathrm{Na}_{2} \mathrm{CO}_{3}$. Хорошие результаты получены также с элюентом, содержащим 1,5 мM N $\mathrm{Na}_{2} \mathrm{CO}_{3}$ и 1 мM $\mathrm{Na}_{2} \mathrm{~B}_{4} \mathrm{O}_{7}$, но время работы подавительной колонки в данном случае немного сокращается $\left[{ }^{16}\right]$. Добавление в состав элюента $\mathrm{NaOH}$ смещает $\mathrm{pH}$ раствора и, соответственно, увеличивает время удерживания фосфат-иона. Недостатком такого элюента является необходимость защиты его от поглощения двуоксида углерода из воздуха.

Селективность ионохроматографического анализа увеличивается с осаждением фосфат-, малат- и сульфат-ионов. Для этого можно применять Ва(OH) 2 или катионит в Ва-форме. Эффективность осаждения увеличивается с добавками органических растворителей, например этилового спирта. В этом случае достигается осаждение как белков, так и коллоидных частиц и исключается тем самым попадание их в разделяющую колонку, что важно для обеспечения большего срока службы колонки при серийных анализах. 
Таблица 1

Результаты определения $\mathrm{NO}_{3}^{-}$колориметрическим методом (1-й и 2-й варианты), одноколоночной (3) и двухколоночной (4) ионной хроматографией и ионометрией (5), мг/кг

\begin{tabular}{|c|c|c|c|c|c|c|c|c|}
\hline \multirow{2}{*}{$\begin{array}{l}\text { Номер } \\
\text { пробы }\end{array}$} & \multirow{2}{*}{\multicolumn{3}{|c|}{ Объект анализа }} & \multicolumn{5}{|c|}{ Метод } \\
\hline & & & & 1 & 2 & 3 & 4 & 5 \\
\hline 1 & \multicolumn{3}{|c|}{ Картофель } & 64 & 60 & 50 & 53 & 73 \\
\hline 2 & \multicolumn{3}{|c|}{ " } & 118 & 114 & 114 & 120 & 127 \\
\hline 3 & \multicolumn{3}{|l|}{$"$} & 76 & 81 & 75 & 80 & 88 \\
\hline 4 & \multirow{2}{*}{\multicolumn{3}{|c|}{ ", }} & 168 & 160 & 160 & 163 & 152 \\
\hline 5 & & & & 180 & 172 & 180 & 175 & 195 \\
\hline 6 & \multicolumn{3}{|l|}{$"$} & 51 & 54 & 59 & 52 & 79 \\
\hline 7 & \multicolumn{3}{|l|}{$"$} & 82 & 78 & 82 & 77 & 88 \\
\hline 8 & \multicolumn{3}{|l|}{$"$} & 296 & 303 & 292 & 300 & 300 \\
\hline 9 & \multicolumn{3}{|l|}{$"$} & 172 & 168 & 180 & 177 & 180 \\
\hline 10 & \multicolumn{3}{|l|}{$"$} & 58 & 64 & 60 & 58 & 81 \\
\hline 11 & \multicolumn{3}{|l|}{, } & 70 & 65 & 69 & 74 & 94 \\
\hline 12 & \multicolumn{3}{|l|}{$"$} & 98 & 95 & 99 & 96 & 105 \\
\hline 13 & \multicolumn{3}{|l|}{$"$} & 125 & 120 & 120 & 124 & 139 \\
\hline 14 & \multicolumn{3}{|l|}{$"$} & 109 & 105 & 100 & 108 & 130 \\
\hline 15 & \multicolumn{3}{|c|}{$"$} & 102 & 101 & 100 & 94 & 110 \\
\hline 16 & \multicolumn{3}{|c|}{ Столовая свекла } & 1480 & 1600 & 1540 & 1590 & 1470 \\
\hline 17 & \multicolumn{3}{|c|}{, } & 2180 & 2350 & 2290 & 2400 & 2400 \\
\hline 18 & \multicolumn{3}{|l|}{$"$} & 1600 & 1640 & 1670 & 1600 & 1700 \\
\hline 19 & \multicolumn{3}{|l|}{$"$} & 1800 & 1590 & 1800 & 1740 & 1790 \\
\hline 20 & $"$ & 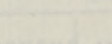 & 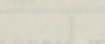 & 3090 & 3000 & 3000 & 2850 & 2900 \\
\hline 21 & $"$ & 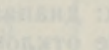 & 607916 & 2990 & 2950 & 2800 & 3000 & 2900 \\
\hline 22 & , & & & 790 & 795 & 800 & 820 & 830 \\
\hline 23 & $"$ & $0=5 x+1$ & 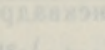 & 1070 & 1090 & 1100 & 1100 & 1080 \\
\hline 24 & $"$ & & & 580 & 600 & 600 & 590 & 610 \\
\hline 25 & $"$ & 60 & & 890 & 900 & 910 & 930 & 900 \\
\hline 26 & $"$ & an & & 4000 & 3900 & 4000 & 3900 & 4100 \\
\hline 27 & $"$ & & & 3800 & 3790 & 3900 & 3800 & 3900 \\
\hline 28 & $"$ & & & 1250 & 1200 & 1200 & 1250 & 1300 \\
\hline 29 & $"$ & & & 1050 & 970 & 1000 & 960 & 1000 \\
\hline 30 & " & & & 3040 & 3000 & 3050 & 3090 & 3100 \\
\hline 31 & Капуста & & & 550 & 590 & 590 & 490 & 620 \\
\hline 32 & , & & & 540 & 580 & 580 & 480 & 780 \\
\hline 33 & " & & & 660 & 650 & 650 & 650 & 900 \\
\hline 34 & ", & & & 980 & 880 & 800 & 740 & 800 \\
\hline 35 & $"$ & & & 120 & - & 139 & 130 & 232 \\
\hline 36 & $"$ & & 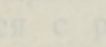 & 170 & - & 175 & 170 & 377 \\
\hline 37 & $"$ & & & 210 & - & 196 & 205 & 220 \\
\hline 38 & $"$ & 8,10 & & 1000 & 880 & 950 & 850 & 1050 \\
\hline 39 & ” & 8,25 & 86,8 & 680 & 690 & 650 & 660 & 830 \\
\hline 40 & " & 901 & 50,0 & 220 & - & 220 & 230 & 250 \\
\hline 41 & " & 2,169 & & 116 & - & 120 & 115 & 190 \\
\hline 42 & ” & & & 86 & - & 80 & 85 & 140 \\
\hline 43 & , & & & 309 & - & 300 & 306 & 290 \\
\hline 44 & " & & 8,11- & 350 & - & 360 & 355 & 350 \\
\hline 45 & ", & 618,07 & 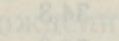 & 73 & - & 70 & 74 & 100 \\
\hline
\end{tabular}


Йспользование детектора по УФФ-абсорбции позволяет повысить селективность анализа, так как максимум поглощения нитрат-иона наблюдается при 193,6 нм [']. Но на этой длине волны сильно поглощают I другие неорганические $\left(\mathrm{Cl}^{-}\right)$и органические (малат) анионы. Поэтому длину волны целесообразно выбирать такой, чтобы при умеренной потере чувствительности снизить влияние малат- и хлорид-ионов. Мы предлагаем использовать длину волны 214 нм.

Данные о содержании $\mathrm{NO}_{3}^{-}$в картофеле и овощах, полученные использованными методами, приведены в табл. 1. При сравнении этих результатов за основу (эталон) выбран вариант 1 колориметрического метода. В качестве реактивов для реакций диазотирования и сочетания использовали сульфаниламид и $\mathrm{N}$ - (нафтил-1) -этилендиамин.

Для количественной оценки результатов, полученных разными методами, вычисляли средние отклонения (систематические расхождения) [19]:

$$
\bar{d}_{n}=\frac{1}{m} \sum_{i=1}^{m}\left(c_{i, n}-c_{i, 1}\right),
$$

где $c_{i, n}-$ концентрация нитрат-иона в $i$-й пробе по методике $n(n=2-$ $5), c_{i, 1}-$ концентрация нитрат-иона в $i$-й пробе по эталонной методике, $m$ - число проб.

Для оценки дисперсии величин $\bar{d}_{n}$ вычисляли соответствующие среднеквадратичные отклонения [19]:

$$
s_{d, n}=\frac{1}{\sqrt{m-1}} \sqrt{\sum_{i=1}^{m}\left(d_{i, n}-\bar{d}_{n}\right)^{2}},
$$

таблица 2

Метрологические характеристики сравниваемых методик: диапазон определяемых содержаний $\mathrm{NO}_{3}^{-}(Д)$, мг/кг; относительные стандартные отклонения в этом диапазоне $\left(s_{r}\right)$; средние отклонения $\left(\bar{d}_{n}\right)$ и среднеквадратичные отклонения $\left(s_{d, n}\right)$, мг/кг; расчетные $\left(t_{\text {расч}}\right)$ и табличные $\left(t_{\text {табл }}\right)$ значения $t$-критерия при

\begin{tabular}{|c|c|c|c|c|c|c|c|}
\hline \multirow[b]{2}{*}{$\begin{array}{r}\text { Объект } \\
\text { анализа }\end{array}$} & \multirow[b]{2}{*}{$\begin{array}{l}\text { Ме- } \\
\text { тод* }\end{array}$} & \multicolumn{6}{|c|}{ Характеристики } \\
\hline & & Д & $s_{r}$ & $d_{n}$ & $s_{d, n}$ & $t_{\text {расч }}$ & $t_{\text {та } 6 \pi}$ \\
\hline \multirow[t]{5}{*}{ Картофель } & 1 & $51-296$ & 0,07 & & & & \\
\hline & 2 & $53-303$ & 0,1 & $-1,93$ & 4,86 & 1,54 & 2,15 \\
\hline & 3 & $50-292$ & 0,06 & $-1,87$ & 5,84 & 1,24 & 2,15 \\
\hline & 4 & $52-300$ & 0,09 & $-1,20$ & 4,80 & 0,97 & 2,15 \\
\hline & 5 & $73-300$ & 0,24 & 11,5 & 10,6 & 4,19 & 2,15 \\
\hline \multirow[t]{5}{*}{$\begin{array}{l}\text { Столовая } \\
\text { свекла }\end{array}$} & 1 & $580-4000$ & 0,06 & & & & \\
\hline & 2 & $600-3900$ & 0,09 & $-15,7$ & 91,2 & 0,67 & 2,15 \\
\hline & 3 & $600-4000$ & 0,06 & 3,33 & 76,3 & 0,17 & 2,15 \\
\hline & 4 & $590-3900$ & 0,1 & 0,67 & 102 & 0,03 & 2,15 \\
\hline & 5 & $610-4100$ & 0,16 & 24,7 & 94,5 & 1,01 & 2,15 \\
\hline \multirow[t]{5}{*}{ Капуста } & 1 & $73-1000$ & 0,07 & & & & \\
\hline & 2 & $580-880$ & 0,11 & - & - & - & - \\
\hline & 3 & $70-950$ & 0,07 & $-11,9$ & 51,6 & 0,89 & 2,15 \\
\hline & 4 & $74-850$ & 0,09 & $-34,3$ & 70,8 & 1,87 & 2,15 \\
\hline & 5 & $140-1050$ & 0,32 & 78,0 & 110 & 2,73 & 2,15 \\
\hline
\end{tabular}

$$
f=14 \text { и } P=0,95
$$

* Название методов см. в подписи к табл. 1. 
где $d_{i, n}=c_{i, n}-\bar{c}_{i, 1}$. Исходя из значений $\vec{d}_{n}$ и $s_{d, n}$ (см. табл. 2) оценивали статистическую значимость отклонения $\bar{d}_{n}$ от нуля. Если расчетное значение

$$
t_{\mathrm{pacq}}=\frac{\left|\bar{d}_{n}\right| \sqrt{m}}{s_{d, n}}
$$

больше табличного $t_{\text {табл }}$, полученные расхождения значимы. Из табл. 2 следует, что расхождение результатов, полученных колориметрическими и ионохроматографическими методами, незначимо, а результатов, полученных ионометрическим методом, значимо для капусты и картофеля. Расхождения обусловлены влиянием находящихся в пробах овощей других анионов, относительно которых нитрат-электрод не обладает достаточной селективностью. Сравнение коэффициентов селективности нитратного электрода приводит к заключению, что основные помехи создают непредельные ди- и монокарбоновые кислоты $\left[{ }^{20}\right]$, например фумаровая и эруковая (цис-13-доказеновая) [15,21]. Ионохроматографическим методом нами найдено, что содержание фумаровой кислоты, участвующей в цикле трикарбоновых кислот, составляет, мг/кг: картофель $3-40$, капуста 50 - 250 и брюква $100-500$. В случае проб картофеля эти результаты согласуются с данными жидкостной хроматографии [15].

Таблица 3

Результаты определения $\mathrm{NO}_{3}^{-}$ионохроматографическим (3) и ионометрическим методом до (5) и после (5') обработки проб $\mathrm{KMnO}_{4}$, мг/кг

\begin{tabular}{|c|c|c|c|c|c|c|c|}
\hline \multirow{2}{*}{$\begin{array}{l}\text { Объект } \\
\text { анализа }\end{array}$} & \multicolumn{3}{|c|}{ Метод } & \multirow{2}{*}{$\begin{array}{l}\text { Объект } \\
\text { анализа }\end{array}$} & \multicolumn{3}{|c|}{ Метод } \\
\hline & 3 & 5 & $5^{\prime}$ & & 3 & 5 & 5, \\
\hline \multirow[t]{6}{*}{ Картофель } & 75 & 100 & 82 & Капуста & 300 & 600 & 340 \\
\hline & 60 & 90 & 66 & & 200 & 450 & 230 \\
\hline & 90 & 129 & 107 & & 400 & 415 & 380 \\
\hline & 55 & 80 & 64 & 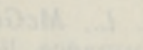 & 160 & 260 & 180 \\
\hline & 100 & 115 & 107 & & 350 & 400 & 340 \\
\hline & & & & & 680 & 930 & 700 \\
\hline
\end{tabular}

Влияние непредельных кислот устраняется при обработке экстракта окислителями, например $\mathrm{KMnO}_{4}$ или $\mathrm{O}_{3}$. Результаты сравнительных анализов после обработки проб $\mathrm{KMnO}_{4}$ при $\mathrm{pH} 2,5$ приведены в табл. 3. Они хорошо согласуются с результатами, полученными ионохроматографическим методом.

\section{Выводы}

1. Определены содержания нитрат-иона в 45 пробах картофеля, капусты и свеклы колориметрическим, ионохроматографическим и ионометрическим методами.

2. Вычислены расхождения между результатами определения концентраций нитрат-иона указанными методами и значимость расхождснций по $t$-критерию. 
3. Систематические погрешности определения нитрат-иона обусловлены влиянием аскорбиновой кислоты (колориметрический метод определения), яблочной кислоты и растворимых фосфатов (двухколоночная понная хроматография) и ряда непредельных органических кислот (ионометрический метод).

4. Показана необходимость окисления непредельных дикарбоновых кислот для устранения их влияния на нитрат-селективный электрод.

\section{Л ИТЕ Р А Т У Р А}

1. Уильямс У. Дж. Определение анионов. М., 1982, 118-142.

2. Шпигун О. А., Золотов Ю. А. Ионная хроматография - метод быстрого и избирательного определения анионов. - Заводск. лаборатория, 1982, № 9, 4-14.

3. Фриц Дж., Гьерде Д., Поланд К. Ионная хроматографня. М., 1984.

4. Haddad, P. R., Heckenberg, A. L. Determination of inorganic anions by highperformance liquid chromatography. - J. Chromatogr., 1984, 300, 357-394.

5. Haldna, O., Palvadre, R., Pentchuk, J., Kleemeier, T. Preparation of low-capacity anion exchange resins for ion chromatography on a methacrylic copolymer matrix. - J. Chromatogr., 1985, 350, 296-298.

6. Аратскова А. А., Орлов В. И., Ячин Я. И. Аналитические возможности ионного хроматографа Цвет-3006. - Ж. анал. хим., 1987, 42, вып. 2, 365-369.

7. Самохвалов С. Г., Прижукова В. Г., Молканова Л. И. Сравнительная характеристика методов определения нитратов в продуктах растениеводства. - В кн.: Канцерогенные $\mathrm{N}$-нитрозосоединения и их предшественники - образование и определение в окружающей среде. Таллин, 1987, 206-208.

8. Пихл В. О., Пенчук Я. О., Ильмоя К. А., Иваск М. Р., Вельс Э. А., Уус Х. К. Ионометрическое определение нитрат-нона в картофеле и овощах. - Уч. зап. Тартуск. ун-та, 1986, вып. 743, 103-116.

9. Kjuus, B. E. Determination of nitrate in agricultural material by the nitrate selective electrode. - Z. anal. Chem., 1986, 323, 264-265.

10. Telling, $G$. M. A brief review of analytical methods for the determination of nitrate and nitrite in foodstuffs. - JARS Sci. Publ., 1978, 18, 49-77.

11. Nicholas, R. A., Fox, J. B. Critical evaluation of the AOAC method of analysis for nitrite in meat. - J. Assoc. Offic. Anal. Chem., 1973, 56, 922-925.

12. Usher, C. D., Telling, G. M. Analysis of nitrate and nitrite in foodstuffs: a critical review. - J. Sci. Food Agric., 1975, 2, 1793-1805.

13. Терней А. Современная органическая химия, 2. М., 1981, 266-273.

14. Чарыков $A$. K. Математическая обработка результатов химического анализа. Л., $1984,142-143$.

15. Bushway, R. J., Bureau, J. L., McGann, D. F. Determination of organic acids in potatoes by high performance liquid chromatography. - J. Food. Sci., 1984, $49,75-81$.

16. Пенчук Я. О., Халдна Ю. Л., Пихл В. О., Ильмоя К. А. Ионохроматографическое определение нитратов в овощах и картофеле. - Уч. зап. Тартуск. ун-та, 1986, вып. $743,168-175$.

17. Hertz, J., Ballenspciger, $U$. Determination of nitrate and other inorganic anions $\left(\mathrm{NO}_{2}{ }^{-}, \mathrm{PO}_{4}{ }^{3-}, \mathrm{Cl}-, \mathrm{SO}_{4}{ }^{2-}\right)$ in salad and vegetables by ion chromatography. Z. Anal. Chem., 1984, 318, 121-123.

18. Энгельгардт X. Жидкостная хроматография при высоких давлениях. М., 1980, 20.

19. Методические основы исследования химического состава горных пород, руд и минералов. М., 1979, 56-68.

20. Senkyr, J., Kouril, $K$. Selectivity coefficients of univalent anions for liquid ionexchange membrane electrodes based on nitrobenzene. - J. Electroanalyt. Chem., 1984, 180, 383-394.

21. Кретович В. Л. Биохимия растений. М., 1980, 245, 406.

Тартуская городская санэпидстанция

Ннститут химии

Академии наук Эстонской ССР
Поступила в редакцию 1/II 1988 
NITRAATIOONI MÄARAMINE KÖGIVILJADES FUOSIKALIS-KEEMILISTE ANALUUSIMEETODITEGA

Kasutades kolorimeetrilist, ioonkromatograafilist ja ionomeetrilist meetodit on määratud nitraatiooni sisaldus neljakümne viies kartuli, punapeedi ja kapsa proovis. Saadud tulemused on omavahel rahuldavas kooskõlas. Erandiks on ionomeetriline meetod, mis annab kōrgemad näitajad kartuli ja kapsa proovides, sest kasutatud ioonselektiivse elektroodi selektiivsus nendes objektides esinevate küllastumata mono- ja dikarboonhapete suhtes ei ole piisav. On leitud, et süstemaatiline kōrva'eka:le väheneb oluliselt, kui kõrvaldada nimetatud happed $\mathrm{KMnO}_{4}$ või $\mathrm{O}_{3}$-ga. Madalate nitraadisisalduste määramisel võivad vigu põhjustada kolorimeetrilise meetodi puhul askorbiinhape, kahekolonnilise ioonkromatograafia puhul ounhape ja lahustuvad fosfaadid ning ionomeetrilise meetodi korral küllastamata mono- ja dikarboonhapped.

Ya. PENTCHUK, O. HALDNA, K. ILMOJA, M. IVASK

\section{DETERMINATION OF NITRATE IONS IN VEGETABLE SAMPLES BY COLORIMETRY, ION CHROMATOGRAPHY AND IONOMETRY}

Three methods (colorimetry after reducting nitrate to nitrite, single- and doublecolumn ion chromatography and ionometry with a nitrate-selective electrode) were used to determine nitrate ions in 45 vegetable samples. The results obtained were in satisfactory agreement, except those obtained by ionometry for potato and cabbage samples. On determining the low content of nitrate ions by colorimetry, an interference due to the presence of ascorbate was observed. By using double-column ion chromatography, the malate and phosphate ions were found to interfere. After removing fumaric and other unsaturated organic acids with $\mathrm{KMnO}_{4}$ or $\mathrm{O}_{3}$, the interference decreased. 